\title{
СОВМЕСТНОЕ КАТАЛИТИЧЕСКОЕ СЖИГАНИЕ САЖИ И ВОДОРОДА В КИПЯЩЕМ СЛОЕ
}

\author{
Языков Николай Алексеевич', \\ yazykov@catalysis.ru
}

\author{
Симонов Александр Дмитриевич', \\ simonov@catalysis.ru \\ 1 Институт катализа им. Г.К. Борескова СО РАН,
Россия, 630090, г. Новосибирск пр. Академика Лаврентьева, 5.
}

Актуальность исследования обусловлена необходимостью обезвреживания выбросов сажи и водорода из печей нанесения углеродных покрытий на сорбенты, которые в основном сжигаются в факельном режиме. Это приводит к образованию термических оксидов азота и не обеспечивает полного сгорания сажи.

Цель: определение оптимальных условий проведения процесса совместного сжигания продуктов пиролиза бутадиена в кипящем слое катализатора глубокого окисления на реальных выбросах смеси сажи и водорода из печи нанесения углеродных покрытий на сорбенты.

Объекты: реальные выбросы смеси сажи и водорода из печи нанесения углеродных покрытий на сорбенты.

Методы: хроматографический анализ отходящих газов из реактора с кипящим слое катализатора при сжигании смеси сажи и водорода, фотоколориметрический анализ газов на содержание оксидов азота с использованием реактива Грисса-Илосвая, весовой метод определения выбросов сажи. Удельную поверхность сажи определяли на основе данных изотермы низкотемпературной адсорбции азота.

Результаты. Определены оптимальные условия проведения процесса совместного сжигания продуктов пиролиза бутадиена в кипящем слое катализатора глубокого окисления на реальных выбросах смеси сажи и водорода из печи нанесения углеродных покрытий на сорбенты. Показано, что при совместном каталитическом сжигании сажи и водорода в кипящем слое промышленного катализатора ИК-12-70 происходит практически полное окисление водорода при температуре на уровне $550{ }^{\circ} \mathrm{C}$, а степень выгорания углерода в виде сажи достигает значения не ниже 99,9\%. Выбросы вредных веществ незначительны: NO

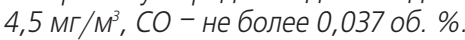

\section{Ключевые слова:}

Кипящий слой, катализатор, водород, сажа, углерод, совместное сжигание, углеродминеральный сорбент.

\section{Введение}

Сжигание твердых топлив, таких как уголь, может быть осуществлено в факельном режиме сжигания в печах при температурах до $1200{ }^{\circ} \mathrm{C}$, при этом топливо подается в пылевидном состоянии $[1,2]$. Для повышения эффективности сжигания используют механическую активацию твердого топлива [3]. Использование печей с кипящим слоем инертного материала, которые позволяют сжигать частицы угля с более крупным гранулометрическим составом, позволяет снизить температуру сжигания твердых топлив до 850-900 ${ }^{\circ} \mathrm{C}$ [4-6]. Основными недостатками этих методов сжигания являются большие габариты аппаратов, высокие температуры отходящих газов, механическая и химическая неполнота сжигания топлив, высокое содержание вредных веществ в отходящих газах.

В Институте катализа СО РАН разработан альтернативный способ сжигания твердых, жидких и газообразных топлив в кипящем слое катализатоpa [7]. Данный метод позволяет сжигать топливо при температурах ниже $800{ }^{\circ} \mathrm{C}$. Это дает возможность значительно уменьшить выброс токсичных веществ, снизить металлоемкость аппарата и понизить температуру отходящих газов. Такой способ позволяет сжигать эффективно различные топлива [8-11]. Присутствие пористого катализатора обеспечивает высокие скорости химических ре- акций, протекающих в аппарате [7, 12]. В связи с этим представляет интерес использование этого способа для сжигания газопылевых выбросов.

Такие газопылевые выбросы образуются при получении углеродминеральных сорбентов. Углеродминеральные сорбенты представляют собой неорганическую пористую матрицу, на которую нанесен углерод. Получить такие сорбенты можно при пиролизе твердых продуктов, содержащих органическую часть или путем нанесения углерода на неорганический пористый носитель. В частности, углеродминеральные сорбенты, которые нашли применение в промышленности, получают из рисовой шелухи, содержащей до 13-29\% $\mathrm{SiO}_{2}$ [13]. При проведении окислительного пиролиза рисовой шелухи, в процессе которого происходит формирование углеродного покрытия на пористой матрице $\mathrm{SiO}_{2}$ и окисление летучих веществ в кипящем слое катализатора полного окисления, образуется углеродминеральный сорбент с площадью удельной поверхности $232 \mathrm{~m}^{2} /$ г в одну стадию [13]. Для получения сорбентов из рисовой шелухи с более высокой площадью удельной поверхности используют активацию с применением, например, $\mathrm{K}_{2} \mathrm{CO}_{3}, \mathrm{Na}_{2} \mathrm{CO}_{3}[14,15]$. В случае обработки рисовой шелухи $\mathrm{K}_{2} \mathrm{CO}_{3}, \mathrm{Na}_{2} \mathrm{CO}_{3}$ при $900{ }^{\circ} \mathrm{C}$ возможно получение сорбентов с площадью удельной поверхности 794-1329 м²/г [14]. При использовании уже карбонизированного продукта при $800{ }^{\circ} \mathrm{C}$ получа- 
ют углеродминеральные сорбенты с площадью удельной поверхности более $2000 \mathrm{~m}^{2} /$ г. Углеродминеральные сорбенты с такой высокой площадью удельной поверхности могут быть использованы в промышленности не только для очистки газов и жидкостей, но и как сырье для получения суперконденсаторов [16].

В медицине используют углеродминеральные сорбенты на основе пористых синтетических неорганических носителей [17-19]. Наиболее широкое применение нашел углеродминеральный сорбент CУMC-1 на основе пористого оксида алюминия с площадью удельной поверхности на уровне $200 \mathrm{~m}^{2} /$, который используется как энтеросорбент и как дополнительный компонент в комплексной терапии различных соматических и хирургических заболеваний [17]. При получении таких сорбентов при разложении, например, бутадиена в печах нанесения углеродных покрытий на сорбенты при температуре $700-900{ }^{\circ} \mathrm{C}$ образующийся углерод наносится на развитую поверхность минерального сорбента не полностью и на выходе из печи образуется смесь сажы и водорода. Такие выбросы часто сжигаются в факельном режиме при высоких температурах с образованием вредных веществ в отходящих газах, при этом наблюдается механическая и химическая неполнота сжигания сажи.

Целью данной работы было определение оптимальных условий совместного сжигания продуктов пиролиза бутадиена в кипящем слое катализатора глубокого окисления на реальных выбросах смеси сажи и водорода из печи нанесения углеродных покрытий на сорбенты.

\section{Экспериментальная часть}

Исследование процесса сжигания смеси водорода и сажи, образующихся при разложении бутадиена в печи нанесения углеродных покрытий, в присутствии катализатора проводили на установке с использованием реактора с кипящим слоем. Принципиальная схема установки показана на рисунке. В работе использовали катализатор ИК-12-70 (ТУ 6-09-32-36-82. 13,2\% $\quad \mathrm{Cr}_{2} \mathrm{O}_{3}$, $6,8 \% \mathrm{CuO}$, остальное $\mathrm{Al}_{2} \mathrm{O}_{3}$ ) производства ОАО «СКТБ Катализатор» с диаметром частиц 2 мм. В качестве сорбента использовали алюминия оксид сферический (ТУ 6-68-139-93) производства ОАО «СКТБ Катализатор» с диаметром частиц 0,4-0,8 мм.

Реактор кипящего слоя для дожигания выбросов водорода и сажи представляет собой цилиндр с внутренним диаметром 120 мм, снабженный неизотермической насадкой для создания градиента температур между зонами сжигания (нижняя часть реактора) и теплосъема (верхняя часть реактора), где установлен теплообменник. Материал реактора - нержавеющая сталь $12 \mathrm{X} 18 \mathrm{H} 10 \mathrm{~T}$. При подаче топлива в виде смеси сажи и водорода, образующихся в печи нанесения углеродных покрытий на сорбенты, в кипящий слой катализатора полного окисления при $440-730{ }^{\circ} \mathrm{C}$ происходит его сгорание до неизотермической решетки в нижней части реактора. Одновременно в верхней части реактора происходит отвод теплоты теплообменником, погруженным в кипящий слой катализатора, что позволяет сжигать горючие продукты при соотношениях с воздухом, близких к стехиометрическим. Смесь сажи и водорода из печи нанесения углеродных покрытий на сорбенты в реактор с кипящим слоем катализатора подавали через трубку с затвором, чтобы частицы катализатора не попадали в печь нанесения углеродных покрытий.

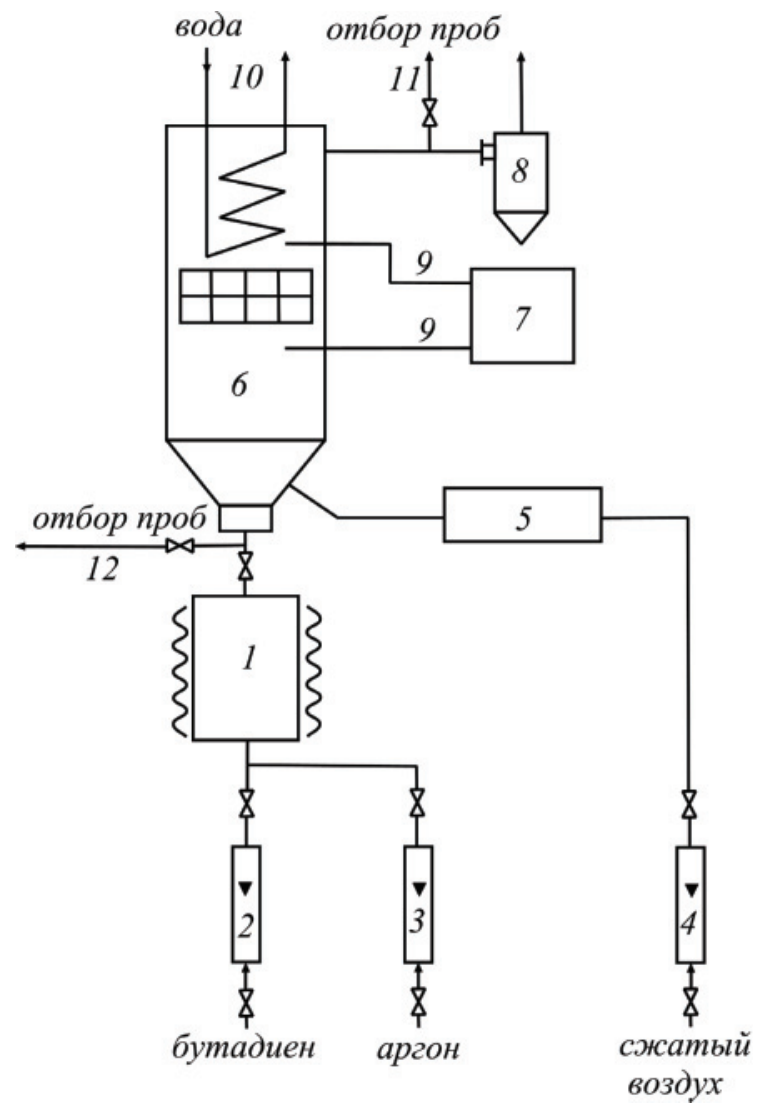

Рисунок. Принципиальная схема установки дожигания выбросов печи нанесения углеродных покрытий на сорбенты: 1 - печь нанесения углеродных покрытий на сорбенты; 2 - роталетр на линии подачи бутадиена; 3 - роталетр на линии подачи аргона; 4 - ротаметр на линии подачи сжатого воздуха; 5 - электрический воздухонагреватель; 6 - реактор с кипящим слоем катализатора; 7 прибор контроля телпературы; 8- ииклон; 9 - терлопары; 10 - теплообменник; 11 - штуиер для отбора проб на выходе из реактора; 12 - штуиер для отбора проб на выходе из печи

Figure. Principle scheme of post-combustion of emissions from furnace for sorbents carbon coating: 1 is the furnace for sorbents carbon coating; 2 is the rotameter on the butadiene feed line; 3 is the rotameter on the argon feed line; 4 is the rotameter on the line supplying compressed air; 5 is the electric heater; 6 is the reactor with a fluidized bed of catalyst; 7 is the temperature control device; 8 is the cyclone; 9 are the thermocouples; 10 is the heat exchanger; 11 is the pipe for sampling at the exit of the reactor; 12 is the pipe for sampling at the exit of the furnace 
Для исключения попадания кислорода в печь 1 для нанесения углеродных покрытий через ротаметр - 3 подавали аргон, после чего через ротаметры - 4 в реактор подавали воздух, который подогревали в электронагревателе - 5 до температуры 700-750 ${ }^{\circ} \mathrm{C}$. После 1 часа разогрева температура кипящего слоя катализатора достигала $350-450{ }^{\circ} \mathrm{C}$. Одновременно температуру в печи с помощью электрического подогревателя поднимали до $700-900{ }^{\circ} \mathrm{C}$. При достижении указанной температуры в печи через ротаметр - 2 подавали бутадиен, который разлагался в печи на водород и сажу $\left(S_{\text {уд }}=150 \mathrm{~m}^{2} / \Gamma, \rho_{\text {нас }}=0,05 \Gamma / \mathrm{cm}^{3}\right)$. Смесь сажи и водорода в токе аргона поступала в реактор, где происходило сгорание сажи и водорода в кипящем слое катализатора. При этом наблюдали повышение температуры в слое катализатора. Газовая смесь поступала на циклон для отделения пыли и затем сбрасывалась в вытяжную систему.

Отбор проб на содержание сажи в газовой смеси после реактора с кипящим слоем осуществляли через штуцер - 11, после печи нанесения углеродных покрытий через штуцер - 12. Для определения содержания сажи газовую смесь откачивали насосом со скоростью 20 л/мин в течение 10 мин через холодильник и фильтр. После отбора пробы фильтр высушивали при комнатной температуре в эксикаторе с силикагелем марки МСМК в течении 24 часов. Количество уловленной сажи определяли по разнице в весе фильтра с сажей и исходным фильтром после сушки в эксикаторе.

Степень выгорания углерода в виде сажи $\beta$ определяли по формуле:

$$
\beta=100\left(G_{\mathrm{C}}{ }^{\mathrm{si}}-G_{\mathrm{C}}{ }^{\mathrm{p}}\right) / G_{\mathrm{C}}{ }^{\text {вп }},
$$

где $G_{\mathrm{C}}{ }^{\text {в }}$ - количество углерода в единицу времени на выходе из печи нанесения углеродных покрытий на сорбенты, г/ч; $G_{\mathrm{C}}{ }^{\mathrm{p}}-$ количество углерода в единицу времени на выходе из реактора с кипящим слоем катализатора, г/ч.

Отбор проб газа для анализа осуществляли с использованием проточных емкостей (3 шт) объемом 1 л с двумя вентилями. Содержание в отходящих газах $\mathrm{H}_{2}, \mathrm{CO}, \mathrm{CH}_{4}, \mathrm{O}_{2}, \mathrm{CO}_{2}$ определяли на хроматографах ЛХМ-80 (Россия) с использованием детекторов по теплопроводности, колонки с $\mathrm{NaX}$ (для определения концентрации $\mathrm{H}_{2}, \mathrm{CO}, \mathrm{CH}_{4}, \mathrm{O}_{2}$ ) и паропаком Q (для определения концентрации $\mathrm{CO}_{2}$ ). Внутренний диаметр колонок 3 мм, длина колонок 2 м. Режим работы хроматографов: ток детектора по теплопроводности 110 мА, температура детектора по теплопроводности $70{ }^{\circ} \mathrm{C}$, температура термостата $20{ }^{\circ} \mathrm{C}$, газ-носитель - гелий, расход гелия $30 \mathrm{~cm}^{3} /$ мин.

Определение $\mathrm{NO}_{\mathrm{x}}$ в отходящих газах из реактора проводили по методу определения концентраций оксидов азота, приведенного в работе [20], с использованием реактива Грисса-Илосвая. Метод основан на взаимодействии нитрит иона и п-аминобензолсульфокислоты (сульфаниловой кислоты) с образованием диазосоединения, которое, реагируя с 1-нафтиламином, дает азокраситель, окра- шивающий раствор от бледно-розового до краснофиолетового цвета. Интенсивность окраски пропорциональна концентрации нитратов. Для измерений оптической плотности растворов после поглощения оксидов азота использовали фотоколориметр КФК-2 (Россия).

Удельную поверхность сажи определяли на основе данных изотермы низкотемпературной адсорбции азота, полученной на автоматизированной волюметрической установке ASAP-2400 фирмы Micromeritics, США.

\section{Результаты и их обсуждение}

Первоначально процесс каталитического сжигания смеси сажи и водорода проводили при загрузке катализатора ИК-12-70 до 7 л, при этом температура в реакторе не превышала $400-450{ }^{\circ} \mathrm{C}$ в результате сильного взаимодействия с теплообменником в верхней части реактора, что приводило к значительному недожогу сажи при подаче смеси углерода с водородом в реактор. Для увеличения температуры слоя катализатора при дожигании выбросов засыпку катализатора уменьшили до 5,0-5,5 л, что обеспечило температуру в слое катализатора $550-730{ }^{\circ} \mathrm{C}$ при выходе на рабочий режим.

таблииа. Результаты испытаний реактора с кипящим слоем катализатора ИК-12-70 при сжигании выбросов водорода и сажи из печи нанесения углеродных покрытий на сорбенты

Table. $\quad$ Test results of the reactor with a fluidized bed of the catalyst IK-12-70 at combustion of soot and hydrogen emissions from the furnace for sorbents carbon coating

\begin{tabular}{|c|c|c|c|c|c|c|c|c|}
\hline$V_{\text {б }}$ & $G_{\mathrm{C}^{\mathrm{I}}}$ & $G_{\mathrm{C}}{ }^{\mathrm{Bn}}$ & $G_{\mathrm{H} 2}{ }^{\mathrm{BI}}$ & $T_{\mathrm{p}}{ }^{\circ} \mathrm{C}$ & $V_{\text {в }}$ & $G_{C^{p}}$ & $\beta$ & $\begin{array}{c}\text { Примечание } \\
\text { Note }\end{array}$ \\
\hline 80,0 & 9,8 & 134,8 & 5,0 & 500 & 7,2 & 0,38 & 0979 & \multirow{6}{*}{$\begin{array}{c}\text { Нанесение C } \\
\text { на сорбент } \\
\text { C coating of } \\
\text { sorbent }\end{array}$} \\
\hline 80,0 & 9,8 & 134,8 & 5,0 & 510 & 7,2 & 0,25 & 9 , & \\
\hline 280,0 & 599,8 & 134,8 & 75,0 & $530-550$ & 7,2 & 0,22 & 99,84 & \\
\hline 121,4 & 260,0 & 60,0 & 32,5 & $440-480$ & 7,2 & 0,38 & 99,37 & \\
\hline 121,4 & 260,0 & 60,0 & 32,5 & $500-530$ & 7,2 & 0,04 & 99,93 & \\
\hline 121,4 & 260,0 & 60,0 & 32,5 & $540-555$ & 7,2 & 0,01 & 99,98 & \\
\hline 210,0 & 449,9 & 449,9 & 56,2 & $550-560$ & 7,2 & 0,35 & 99,92 & \multirow{8}{*}{$\begin{array}{c}\text { Без сорбента } \\
\text { Without } \\
\text { sorbent }\end{array}$} \\
\hline 240,0 & 514,1 & 514,1 & 64,3 & $540-570$ & 7,2 & 0,72 & 99,86 & \\
\hline 240,0 & 514,1 & 514,1 & 64,3 & 600 & 7,2 & 0,72 & 99,86 & \\
\hline 60,0 & 128,5 & 128,5 & 16,1 & \begin{tabular}{|l|}
$400-490$ \\
\end{tabular} & 6,0 & 1,28 & 99,0 & \\
\hline 60,0 & 128,5 & 128,5 & 16,1 & $590-640$ & 6,0 & 1,00 & 99,22 & \\
\hline 60,0 & 128,5 & 128,5 & 16,1 & \begin{tabular}{|l|}
$650-730$ \\
\end{tabular} & 6,0 & 0,92 & 99,28 & \\
\hline 100,0 & 214,2 & 214,2 & 26,8 & $560-570$ & 6,3 & 0,24 & 99,87 & \\
\hline 100,0 & 214,2 & 214,2 & 26,8 & $580-590$ & 6,3 & 0,17 & 99,92 & \\
\hline
\end{tabular}

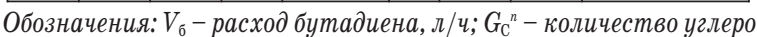
да, образующегося в единииу времени в печи нанесения углеродных покрытий, г/ч; $G_{\mathrm{H} 2}{ }^{\text {вn }}$ - количество водорода на выходе из печи нанесения углеродных покрытий, г/ч; $T_{\mathrm{p}}{ }^{\circ} \mathrm{C}$ - температура в кипящел слое катализатора; $V_{\text {в }}$ - расход воздуха на сжигание слеси сажи и водорода, $м^{3} /$ ч; $\beta$ - степень выгорания углерода, \%.

Description: $V_{6}$ is the consumption of butadiene, $\mathrm{g} / \mathrm{h} ; \mathrm{G}_{\mathrm{C}}{ }^{n}$ is the amount of carbon produced per unit of time in the furnace for sorbents carbon coating, $g / h ; G_{\mathrm{H} 2}{ }^{\text {in }}$ is the amount of hydrogen at the outlet of the furnace for sorbents carbon coating, $g / h ; T_{\mathrm{p}}{ }^{\circ} \mathrm{C}$ is the temperature in the fluidized bed of the catalyst; $V_{\mathrm{B}}$ is the air volume for combustion of a mixture of soot and hydrogen, $m^{3} / h$; $\beta$ is the burn-off degree of soot, $\%$. 
Дальнейшее испытание установки проводили при загрузке катализатора ИК-12-70 5,0-5,5 л. Разложение проводили в печи как при нанесении углеродных покрытий на сорбент, так и в отсутствии сорбента.

Сжигание выбросов печи нанесения углеродных покрытий на сорбенты при температурах кипящего слоя катализатора ИК-12-70 550-600 ${ }^{\circ} \mathrm{C}$ позволяет достигнуть степени выгорания сажи 99,64-99,98 \% . Следует отметить, что количество водорода в выбросах не оказывает существенного влияния на процесс сгорания частиц сажи. Например, при весовом соотношении углерода и водорода в выбросах 1,80-1,85, когда за счет нанесения углерода на сорбенты содержание углерода в выбросах снижается, степень выгорания сажи при температуре $550{ }^{\circ} \mathrm{C}$ составило 99,94-99,98 \% . При весовом соотношении углерода и водорода, равном 8,0 , когда разложение бутадиена происходит без сорбентов в печи, при той же температуре в реактоpe с кипящим слоем катализатора степень выгорания сажи составила 99,92-99,86\% , при этом содержание вредных веществ во всех случаях незначи-

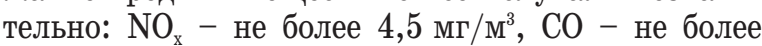
0,037 об. \% . Метана и водорода на выходе из реактора с кипящим слоем катализатора не обнаружено.

\section{СПИСОК ЛИТЕРАТУРЫ}

1. Кнорре Г.Ф. Топочные процессы. - М; Л: Госэнергоиздат, 1951. $-328 \mathrm{c}$

2. Канторович Б.В. Основы теории горения и газификации твердого топлива. - М: Изд-во АН СССР, 1958. - 601 с.

3. Кузнецов А.В., Бутаков Е.Б. Исследование влияния механической активации на горение угольного топлива // Известия Томского политехнического университета. Инжиниринг георесурсов. - 2016. - Т. 327. - № 6. - С. 37-44

4. Кубин М. Сжигание твердого топлива в кипящем слое. - М: Энергоиздат, 1987. - 112 c.

5. Oka S.N. Fluidized Bed Combastion. - New York, Basel: Marcell Dekker, Ink, 2004. - $590 \mathrm{p}$

6. Yates J.G. Fundamentals of fluidized bed chemical processes. London: Butterworths, 1983. - $289 \mathrm{p}$.

7. Боресков Г.К. Гетерогенный катализ. - М: Наука,1986. $304 \mathrm{c.}$

8. Каталитические теплофикационные устройства для решения экологических и энергетических проблем / В.Н. Пармон, З.Р. Исмагилов, В.А. Кириллов, А.Д. Симонов // Катализ в промышленности. - 2002. - № 3. - С. 20-29.

9. Опыт эксплуатации водогрейных котлов с каталитическим сжиганием жидкого и твердого топлива в псевдоожиженном слое / А.Д. Симонов, Н.А. Языков, А.С. Афлятунов, И.А. Федоров, В.А. Яковлев, В.Н. Пармон // Альтернативная энергетика и экология. -2014 . - № 19 (159). - С. 70-85.

10. Industrial experience of heat supply by catalytic installations / A.D. Simonov, N.A. Yazykov, N.A. Vedyakin, G.A. Lavrov, V.N. Parmon // Catalysis Today. - 2000. - № 60. - P. 139-145.

11. Features of sulfur oils catalytic combustion in fluidized bed / N.A. Yazykov, Yu.V. Dubinin, A.D. Simonov, S.I. Reshetnikov, V.A. Yakovlev // Chemical Engineering Journal. - 2016. V. 283. - P. 649-655.

12. Mutiphase catalytic reactors: theory, design, manufacturing and application / Ed. by Z.I. Önsan, A.K. Avci. - Hoboken, New Jersey: John Wiley \& Sons Inc., 2016. - 381 p.
Таким образом, не зависимо от концентрации водорода на выходе из печи нанесения углеродных покрытий на сорбенты, при температуре проведения процесса каталитического сжигания в кипящем слое на уровне $550{ }^{\circ} \mathrm{C}$ достигается степень выгорания сажи не ниже $99,9 \%$.

\section{Заключение}

Проведено исследование процесса совместного сжигания сажи и водорода, образующихся из бутадиена в печи нанесения углеродных покрытий на сорбент, в кипящем слое катализатора глубокого окисления на реальных выбросах смеси, определены оптимальные условия проведения процесса. Показано, что при температуре процесса на уровне $550{ }^{\circ} \mathrm{C}$ происходит практически полное окисление водорода, при этом достигается степень выгорания частиц сажи не ниже 99,9 \%, а выбросы вредных веществ незначительны: $\mathrm{NO}_{\text {х }}$ не более $4,5 \mathrm{Mr} / \mathrm{M}^{3}$, $\mathrm{CO}$ - не более 0,037 об. \% .

Каталитический способ сжигания в кипящем слое может быть использован для эффективного сжигания выбросов печей нанесения углеродных покрытий на минеральные сорбенты.

Работа выполнена в ралках государственного задания ФГБУН ИК СО РАН (проект № 0303-2016-0012).

13. Larichev Yu.V, Yeletsky P.M., Yakovlev V.A. Study of silica templates in the rice husk and the carbon-silica nanocomposites produced from rice husk // Journal of Physics and Chemistry of Solids. - 2015. - V. 87. - P. 58-63.

14. Получение активированного угля пиролизом рисовой шелухи Вьетнама / В.В. Коробочкин, М.Х. Нгуен, Н.В. Усольцева, В.Т. Нгуен // Известия Томского политехнического университета. Инжиниринг георесурсов. - 2017. - Т. 328. - № 5. C. $6-15$.

15. Synthesis of mesoporous carbons by leaching out natural silica templates of rice husk / P.M. Yeletsky, V.A. Yakovlev, M.S. Mel'gunov, V.N. Parmon // Microporous and Mesoporous Materials. - 2009. - V. 121. - P. 34-40.

16. Rice Husk Derived Activated Carbon/Polyaniline Composites as Active Materials for Supercapacitors / M.V. Lebedeva, A.B. Ayupov, P.M. Yeletsky, V.N. Parmon // International Journal of Electrochemical Science. - 2018. - V. 13. - P. 3674-3690.

17. Рачковская Л.Н. Углеродминеральные сорбенты для медицины. - Новосибирск: СО РАСХН, 1996. - 220 с.

18. Биологические свойства сорбентов и перспективы их применения / Ю.И. Бородин, В.И. Коненков, В.Н. Пармон, М.С. Любарский, Л.Н. Рачковская, Н.П. Бгатова, А.Ю. Летягин // Успехи современной биологии. - 2014. - Т. 134. - № 3. C. $236-248$.

19. Модифицированные сорбенты для практического здравоохранения / Л.Н. Рачковская, А.Ю. Летягин, В.А. Бурмистров, М.А. Королев, Н.Е. Гельфонд, Ю.И. Бородин, В.И. Коненков // Сибирский научный медицинский журнал. - 2015. - Т. 35. № 2. - C. 47-54.

20. Чибисова Н.В. Практикум по экологической химии. - Калининград: Изд-во Калининградского университета, 1999. - 94 с.

Поступила 21.11.2018 г. 


\section{Информация об авторах}

Языков Н.A., кандидат технических наук, научный сотрудник лаборатории каталитических процессов переработки возобновляемого сырья Института катализа им. Г.К. Борескова СО РАН.

Симонов А.Д., кандидат химических наук, ведущий инженер лаборатории каталитических процессов переработки возобновляемого сырья Института катализа им. Г.К. Борескова СО РАН. 


\title{
CATALYTIC CO-COMBUSTION OF SOOT AND HYDROGEN IN FLUIDIZED BED
}

\author{
Nikolay N. Yazykov', \\ yazykov@catalysis.ru
}

\author{
Alexandr D. Simonov', \\ simonov@catalysis.ru \\ 1 Boreskov Institute of Catalysis of the Siberian Branch of the Russian Academy of Sciences, \\ 5, Acad. Lavrentiev avenue, Novosibirsk, 630090, Russia.
}

The relevance of the research is caused by the need to neutralize the emissions of soot and hydrogen from furnaces for sorbents carbon coating, which are mainly burned in the fire mode. This leads to formation of thermal nitrogen oxides and does not provide complete combustion of soot.

The aim of the research is to determine the optimum conditions of co-combustion of the butadiene pyrolysis products in the fluidized bed of deep oxidation catalyst of real emissions of soot and hydrogen mixture from the furnace for sorbents carbon coating.

Objects: real emissions of a mixture of soot and hydrogen from the furnace for sorbents carbon coating.

Methods: chromatographic analysis of flue gases from the reactor with a fluidized layer of the catalyst after combustion of the mixture of soot and hydrogen, photocolorimetric gas analysis on the content of nitrogen oxides using Griess-llosvay reagent, gravimetric method for determining soot emissions. The specific surface area of soot was determined on the basis of low-temperature nitrogen adsorption isotherm data.

Result. The authors have determined the optimum conditions of co-combustion of butadiene pyrolysis products in the fluidized bed of deep oxidation catalyst of real emissions of the mixture of soot and hydrogen from the furnace for sorbents carbon coating. It is shown that during the catalytic co-combustion of soot and hydrogen in the fluidized bed of the industrial catalyst IC-12-70 almost complete combustion of hydrogen occurs at a $550{ }^{\circ} \mathrm{C}$, and the degree of carbon burn-off in the form of soot reaches a value of not less than 99,9 \%. Emissions of harmful substances are insignificant: $\mathrm{NO}_{x}$ is not more than $4,5 \mathrm{mg} / \mathrm{m}^{3}$, CO is not more than 0,037 vol. \%.

\section{Key words:}

Fluidized bed, catalyst, hydrogen, soot, carbon, co-combustion, carbon-mineral sorbent.

This work was carried out within the framework of budget project no. 0303-2016-0012 for Boreskov Institute of Catalysis.

\section{REFERENCES}

1. Knorre G.F. Topochnye protsessy [Combustion processes]. Moscow; Leningrad, Gosenergoizdat Publ., 1951. 328 p.

2. Kantorovich V.B. Osnovy teorii goreniya i gazifikatsii tverdogo topliva [Fundamentals of the theory of combustion and gasification of solid fuels]. Moscow, AS USSR Publ. house, 1958. $601 \mathrm{p}$.

3. Kuznetsov A.V., Butakov E.B. A study of the influence of mechanical activation on the combustion of coal fuel. Bulletin of Tomsk Polytechnic University. Geo Assets Engineering, 2016, vol. 327, no. 6, pp. 37-44. In Rus.

4. Kubin M. Szhiganie tverdogo topliva v kipyashchem sloe [Solid fuel combustion in the fluidized bed]. Moscow, Energoizdat Publ., $1987.112 \mathrm{p}$.

5. Oka S.N. Fluidized Bed Combustion. New York, Basel, Marcell Dekker, Ink, 2004. $590 \mathrm{p}$

6. Yates J.G. Fundamentals of fluidized bed chemical processes. London, Butterworths, 1983. 289 p.

7. Boreskov G.K. Geterogenny kataliz [Heterogeneous catalysis]. Moscow, Nauka Publ., 1986. 304 p.

8. Parmon V.N., Ismagilov Z.R., Kirillov V.A., Simonov A.D. Catalytic heating devices for solving environmental and energy problems. Catalysis in Industry, 2002, no. 3, pp. 20-29. In Rus.

9. Simonov A.D., Yazykov N.A., Aflyatunov A.S., Fedorov I.A., Yakovlev V.A., Parmon V.N. The experience of operating boilers with catalytic combustion of liquid and solid fuels in fluidized bed. Alternative Energy and Ecology, 2014, no. 19 (159), pp. 70-85. In Rus.

10. Simonov A.D., Yazykov N.A., Vedyakin P.I., Lavrov G.A., Parmon V.N. Industrial experience of heat supply by catalytic installations. Catalysis Today, 2000, no. 60, pp. 139-145.
11. Yazykov N.A., Dubinin Yu.V., Simonov A.D., Reshetnikov S.I., Yakovlev V.A. Features of sulfur oils catalytic combustion in fluidized bed. Chemical Engineering Journal, 2016, vol. 283, pp. 649-655.

12. Mutiphase catalytic reactors: theory, design, manufacturing and application. Eds. Z.I. Önsan, A.K. Avci. Hoboken, New Jersey, John Wiley \& Sons Inc., 2016. 381 p.

13. Larichev Yu.V., Yeletsky P.M., Yakovlev V.A. Study of silica templates in the rice husk and the carbon-silica nanocomposites produced from rice husk. Journal of Physics and Chemistry of $\mathrm{SO}_{0}$ lids, 2015, vol. 87, pp. 58-63.

14. Korobochkin V.V., Nguyen M.H., Usoltseva N.V., Nguyen V.T. production of activated carbon by pyrolysis of rice husk of Vietnam. Bulletin of Tomsk Polytechnic University. Geo Assets Engineering, 2017, vol. 328, no. 5. pp. 6-15. In Rus.

15. Yeletsky P.M., Yakovlev V.A., Mel'gunov M.S., Parmon V.N. Synthesis of mesoporous carbons by leaching out natural silica templates of rice husk. Microporous and Mesoporous Materials, 2009, vol. 121, pp. 34-40.

16. Lebedeva M.V., Ayupov A.B., Yeletsky P.M., Parmon V.N. Rice Husk Derived Activated Carbon/Polyaniline Composites as Active Materials for Supercapacitors. International Journal of Electrochemical Science, 2018, vol. 13, pp. 3674-3690.

17. Rachkovskaya L.N. Uglerodmineralnye sorbenty dlya meditsyny [Carbon-mineral sorbents for medicine]. Novosibirsk, Russian Academy of agricultural Sciences Publ., 1996. 220 p.

18. Borodin Yu.I., Konenkov V.I., Parmon V.N., Lyubarsky M.S., Rachkovskaya L.N., Bgatova N.P., Letyagin A.Yu. Biological properties of sorbents and prospects of their application. Successes of Modern Biology, 2014, vol. 134, no. 3, pp. 236-248. In Rus. 
19. Rachkovskaya L.N., Letyagin A.Yu., Burmistrov V.A., Korolev M.A., Gelfond N.E., Borodin Y.I., Konenkov V.I. Modified sorbents for practical public health. Siberian Scientific Medical Journal, 2015. vol. 35, no. 2, pp. 47-54. In Rus.
20. Chibisova N.V. Praktikum po ekologicheskoy khimii [Workshop on environmental chemistry]. Kaliningrad, Kaliningrad University Publ. house, $1999.94 \mathrm{p}$.

Received: 21 November 2018.

\section{Information about the authors}

Nikolay N. Yazykov, Cand. Sc., scientist worker, Boreskov Institute of Catalysis of the Siberian Branch of the Russian Academy of Sciences.

Alexandr D. Simonov, Cand. Sc., leading engineer, Boreskov Institute of Catalysis of the Siberian Branch of the Russian Academy of Sciences. 